\title{
Study on Influencing Factors for Investment Strategy of Chinese Cultural Industry
}

\author{
Zhang Guiling \\ Accounting and Finance Research Center, Collaborative Innovation Center for \\ Aviation Economy Development of Henan Province, Zhengzhou University of \\ Aeronautics, Zhengzhou, 450046, China \\ financepaperzhang@126.com
}

\begin{abstract}
This paper analyzes relations of influence of the four factors, including corporate external financing capacity, governance mechanism, systems and talents environment, on longsighted investment strategy for cultural industry using the least square method of regression analysis by data samples. The study finds enhancing corporate external financing capacity, improving its governance mechanism, optimizing its systems and talents environment for a competitive promotion and a strategic investment transformation from shortsighted to longsighted for culture industry.
\end{abstract}

Keywords: Culture industry; longsighted investment strategy; external financing capacity; corporate governance mechanism

\section{Introduction}

It has been upgraded to the Chinese Government's strategy to strive to develop cultural industry. A cultural enterprise is the carrier of the cultural industry, and its development and competitiveness are affected and restrained by corporate investment strategy, which refers to the overall planning made for investment activity in order to maintain and expand the production and operation scales based on the enterprise's comprehensive business strategy requirements. The corporate investment strategies are classified into shortsighted and longsighted investment strategies according to corporate investment for a short-term performance or long-term value maximization, and the selection of its types is affected by such factors as corporate external financing capacity, governance mechanism, systems and talents environment.

By the samples of survey data from questionnaires, the paper is intended to conduct the empirical analysis on corporate investment strategy types and the relations of corporate external financing capacity, governance mechanism, systems and talents environment, and reveals key factors influencing investment strategy of cultural industry, in order to provide the guidance for governments and enterprise development.

\section{Theoretical Hypotheses}

\subsection{The Relation of Influence of Corporate External Financing Capacity on Its Investment Strategy}

A culture industry enterprise needs capital support in its investment behaviors, which mainly depends on external financing in addition to internal financing by profit retention. When having a stronger external financing capacity, it can raise the long-term funds for its scale expansion in terms of long-term liabilities, and take advantage of financial and tax shield effects of the long-term liabilities, so as to realize the strategy of its long-term value maximization. By equity financing, particularly listing financing, it can collect its 
owned funds, not only improving its further credit in liabilities and financing and gaining more business reputation, product market shares and competitiveness, but also seeking the market values by market pricing mechanism by financing and listing. The cultural company more tends to the longsighted investment strategy when it has a stronger external financing capacity. Otherwise, it is still more apt to the shortsighted investment one in consideration of capital demand, time limit of demand and risks of investment projects when it has a weak financing capacity. Based on above analyses, this paper sets forth the following hypothesis:

H1: A company is more inclined to the longsighted investment strategy when it has a stronger corporate external financing capacity.

\subsection{The Relation of Influence of Corporate Governance Mechanism on Investment Strategy}

A cultural industry enterprise may be affected and restricted by corporate governance mechanism in its investment behaviors. In the modern company with separation of ownership and control, the manager's objective is often deviate from the owner's, especially in the event of asymmetrical information and incomplete contracts, that is, the former pursues for the shortsighted investment for his own interests maximization, while the latter longs for the longsighted investment for his own wealth maximization. The agency theory believes the manager and the owner can have a unity of objectives by designing feasible corporate governance mechanism. The corporate governance includes external and internal governance. The former mainly refers to the governance in the competitive market of manager and products, that is, whether the manager is employed in a competitive market, whether the product is monopolized by the government. If its manager is recruited and appointed by the government departments, his position is less threatened in the market. Due to the short-term appraisals to the manager, so he may tend to the shortsighted investment strategy so as to hold on his position; otherwise, he may tend to the longsighted investment strategy. If the products are priced not by market competition but the government monopoly, the manager may tend to the shortsighted investment strategy without the external competitive pressure; otherwise, he may tend to the longsighted one. From the internal governance, we can see due to larger risks in most of investment projects in cultural industries and its lag effects in earnings, when the managers are given stock equity remuneration (especially share option), the managers are stimulated to engage in high-risk projects, and vice versa. Owing to asymmetrical information, the manager can realize his own benefit by the shortsighted investment strategy. The agency theory holds that the manager's shortsighted investment strategy can be corrected by effective supervision mechanism to realize the corporate longsighted investment strategy. Based on above analyses, the paper puts forward the following hypothesis:

H2: A company is more inclined to the longsighted investment strategy when its governance mechanism is more perfect.

\subsection{The Relation of Influence of Corporate Systems on Investment Strategy}

The investment behaviors of a cultural industry enterprise are affected and restricted by its systems. In current China, the enterprises engaged in cultural production activities and services provided are mainly state-owned enterprises. The former mostly are from restructuring of previous public institutions, and they are run by government departments without separation of administration and enterprises, so that management departments of state-owned properties excessively intervened in corporate behaviors. The short-term official appraisals result in the shortsighted investment behaviors for state owned enterprises controlled by governmental officials. The multi-tier principal-agent relationships exist in state-owned business, which lead to not only arbitrary orders from 
governmental departments but also short-term investment behaviors of the managers for their self-interests. On the contrary, when government and enterprise responsibilities are separated and the corporate systems are established, an enterprise can seize market opportunities by market behaviors. By this way, a cultural firm is more inclined to the longsighted investment strategy under the competitive pressure and interest driving. Based on above analyses, the paper puts forward the following hypothesis:

H3: A company is more inclined to the longsighted investment strategy when its systems are well established.

\subsection{The Relation of Influence of Talents Environment on Corporate Investment Strategy}

Modern cultural industry enterprise is developed mainly by applying modern technical tools. The traditional cultures are carried forward sufficiently and the foreign cultures are elaborately extracted to satisfy the demands of human beings for intellectual and artistic products and services with sustainable innovation. By this way, the cultural firms can win in fierce competition. So innovation is the footstone of cultural industry, and talents are the carrier of innovation. The modern cultural industry not only needs innovative-form technical talents but also innovative-type management ones. Talents can not only influence development of a cultural industry, but also restrict its investment behaviors. When a cultural firm is expanding its scale, seizing market opportunities, merging others companies, operating multi-nationally, as well as engaging in high risk investment projects, its long-term development strategy can be carried out successfully if it can recruit required technical and management talents timely. The successful long-term development strategy can strengthen further corporate longsighted investment strategy. Otherwise, if it can not recruit talents in implementation of its long-term investment strategy, then it is difficult to carry out the investment project, and eventually, its long-term investment projects may fail. The investment projects that fail force the company to back to short-term investment behaviors. Recruitment of talents is affected by both corporate incentive mechanism and regional talents environment where the company is located. From the global cultural industry development, the governments of various countries or regions in the world scramble talents in humanity environment cultivation, talent treatments and human settlement environment so as to gain competitive edge in cultural industry. For this reason, when the talents environment becomes good in its operation, the talents in need are gained easily for corporate strategic investment, so the company is more inclined to the longsighted investment strategy. Otherwise, when the talents environment becomes poor in its operation, the talents in need are not gained easily for corporate strategic investment, so the company is more inclined to the shortsighted investment strategy. Based on above analyses, the paper puts forward the following hypothesis:

H4: A company is more inclined to the longsighted investment strategy when its talents environment is well improved.

\section{Research Design}

\subsection{Model Design}

According to the hypotheses in this study, the regression models for longsighted investment strategy (Model I and II) are designed as follows:

$$
\begin{aligned}
& I V M=\alpha_{0}+\alpha_{1} E T F A+\alpha_{2} C G F A+\alpha_{3} I S F A+\alpha_{4} T E F A+\mu \\
& L T R=\beta_{0}+\beta_{1} E T F A+\beta_{2} C G F A+\beta_{3} I S F A+\beta_{4} T E F A+\xi
\end{aligned}
$$


In Model I-II, IVM/LTR are explained variables; test variables are ETFA/ CGFA/ISFA and TEFA. ETFA has two sub-variables (EFA and DFA);CGFA has four sub-variables (MMA/PCM/MRI / SPM); ISFA has two sub-variables (SGE /SOO); TEFA has three sub-variables (HMN/TTT / HSE); controllable variables are FPFA and FEEF, FPFA has two sub-variables (PFS/ TRF), and FEEF has two sub-variables (ITE/ FSY). $\alpha_{0}$ and $\beta_{0}$ are constant; $\alpha_{1}-\alpha_{4}, \beta_{1}-\beta_{4}$ are regression coefficient of Model I -II, respectively. $\mu, \xi$ are the residual of Model I -II.

\subsection{Indicator Design}

Table 1. The Variables and Symbols of Influencing Factors on Cultural Industry Investment Strategy

\begin{tabular}{|c|c|c|c|c|}
\hline \multirow{2}{*}{ Variables } & \multicolumn{2}{|c|}{ First level variables } & \multicolumn{2}{|c|}{ Second level variables } \\
\hline & Name & Symbol & Name & Symbol \\
\hline \multirow{3}{*}{$\begin{array}{l}\text { Explained } \\
\text { variables }\end{array}$} & \multirow{3}{*}{$\begin{array}{l}\text { Longsighted investment } \\
\text { strategy }\end{array}$} & \multirow{3}{*}{ LTIS } & $\begin{array}{l}\text { Investment value } \\
\text { maximization }\end{array}$ & IVM \\
\hline & & & Long term investment & LTR \\
\hline & & & & \\
\hline \multirow{11}{*}{ Variables } & \multirow{2}{*}{$\begin{array}{l}\text { External financing } \\
\text { capacity }\end{array}$} & \multirow{2}{*}{ ETFA } & Equity financing capacity & EFA \\
\hline & & & Debt financing capacity & DFA \\
\hline & \multirow{4}{*}{$\begin{array}{l}\text { Corporate governance } \\
\text { mechanism }\end{array}$} & \multirow{4}{*}{ CGFA } & $\begin{array}{c}\text { Manager competition } \\
\text { market }\end{array}$ & $\mathrm{MCM}$ \\
\hline & & & Product competition market & PCM \\
\hline & & & Management incentives & MIV \\
\hline & & & Supervision mechanism & SPM \\
\hline & \multirow{2}{*}{ Institution and system } & \multirow{2}{*}{ ISFA } & $\begin{array}{c}\text { Separation of government and } \\
\text { enterprise }\end{array}$ & SGE \\
\hline & & & $\begin{array}{c}\text { Separation of ownership and } \\
\text { control }\end{array}$ & SOO \\
\hline & \multirow{3}{*}{ Talents environment } & \multirow{3}{*}{ TEFA } & Humanity environment & HMN \\
\hline & & & Talent treatment & TTT \\
\hline & & & $\begin{array}{c}\text { Human settlement } \\
\text { environment }\end{array}$ & HSE \\
\hline \multirow{4}{*}{$\begin{array}{l}\text { Control } \\
\text { variables }\end{array}$} & \multirow{2}{*}{ Favorable policy } & \multirow{2}{*}{ FPFA } & Government funds support & GFS \\
\hline & & & Tax preference & TRF \\
\hline & \multirow{2}{*}{$\begin{array}{c}\text { Financing ecological } \\
\text { environment }\end{array}$} & \multirow{2}{*}{ FEEF } & Integrity environment & ITE \\
\hline & & & Financing system & FSY \\
\hline
\end{tabular}

In Table 1, the explained variable-longsighted investment strategy (LTIS) contains two second-level variable indexes: investment value maximization (VLM) and long-term investment resource (LTR).

In Table 1, Test variables include external financing capacity (ETFA), corporate governance mechanism (CGFA), institution and system (ISFA) and talents environment (TEFA); and as the first level variable, external financing capacity (ETFA) contains two second level variables: equity financing capacity (EFA) and debt financing capacity (DFA). Corporate governance mechanism (CGFA) contains external governance (including manager competition market(MCM) and product competition market(PCM)) and internal governance (including management incentive mechanism (MIV) and supervision mechanism(SPM)); Institution and system (ISFA) contains separation of government and enterprise (SGE), separation of ownership and control(SOO); Talents 
environment (TEFA) contain Humanity environment(HMN),talent treatment(TTT)and human settlement environment(HSE).

The controllable variables are favorable policy factors (FPFA) and financing ecological environment factors (FEEF). Favorable policy factors (FPFA) contains two second level indicators: government funds support (GFS) and tax preference (TRF). Financing ecological environment factors (FEEF ) contain two second level indicators: integrity environment(ITE) and financing system(FSY).

\subsection{Data Sources}

In order to understand deeply and extensively the influencing factors and process of investment strategy of cultural industry, the questionnaire in this paper is designed strictly according to the logic sequences proposed by scholars such as Churchill (1979), Dunn (1994) and Gerbing \& Anderson (1988). First, the literatures associated with influencing factors on investment and financing for cultural industries were summed up for 19 variable indexes; then the questionnaire was designed, where the "question" was made by Likert Scale ("1" means "less degree", and "7" means "great degree"); finally, the questionnaires were administrated to senior managers in cultural enterprises, cultural specialists who study cultural enterprises and financial experts. 300 questionnaires were released, and 280 were returned, with a return rate of 93.3\%. 24 questionnaires were unqualified, and 256 valid questionnaires were returned with a valid recovery rate of $85.3 \%$.

\section{Empirical Results and Analysis}

\subsection{Correlation Analysis}

This paper uses SPSS 17.0 to analyze the correlations of the variables; the results are listed in Table 2, and Table 3. The correlation coefficients of influence factors of cultural industry longsighted investment strategy are less than 0.5 , most of the coefficients are less than 0.4 , which indicates that the colinearity between variables is not high, and we can do regression analysis.

Table 2. The Correlation Analysis of Influence Factors of Cultural Industry Longsighted Investment Strategy (1)

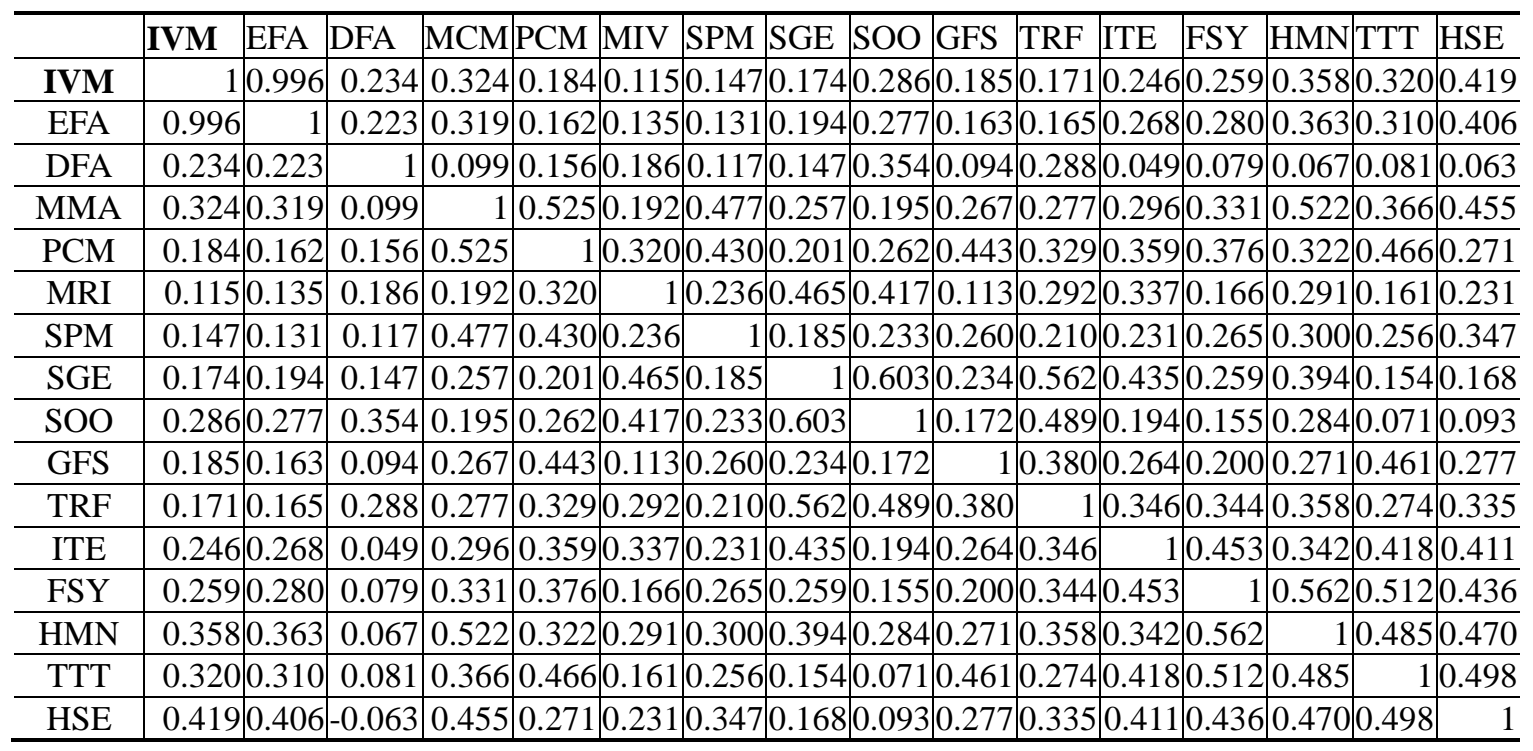


Table 3. The Correlation Analysis of Influence Factors of Cultural Industry Longsighted Investment Strategy (2)

\begin{tabular}{l|r|r|r|r|r|r|r|r|r|r|r|r|r|r|r|r}
\hline & LTR & EFA & DFA & MMA & PCM & MRI & SPM & SGE & SOO & GFS & TRF & ITE & FSY & HMN & TTT & HSE \\
\hline LTR & 1 & 0.668 & 0.020 & 0.367 & 0.448 & 0.147 & 0.429 & 0.273 & 0.308 & 0.403 & 0.345 & 0.324 & 0.186 & 0.447 & 0.334 & 0.386 \\
\hline EFA & 0.668 & 1 & 0.044 & 0.440 & 0.358 & 0.192 & 0.340 & 0.317 & 0.372 & 0.382 & 0.302 & 0.402 & 0.347 & 0.535 & 0.459 & 0.537 \\
\hline DFA & 0.020 & 0.044 & 1 & 0.095 & 0.091 & 0.062 & 0.211 & 0.036 & 0.078 & 0.100 & 0.006 & 0.093 & 0.046 & 0.052 & 0.031 & 0.075 \\
\hline MMA & 0.367 & 0.440 & 0.095 & 1 & 0.583 & 0.225 & 0.544 & 0.325 & 0.259 & 0.375 & 0.344 & 0.375 & 0.382 & 0.593 & 0.453 & 0.532 \\
\hline PCM & 0.448 & 0.358 & 0.091 & 0.583 & 1 & 0.350 & 0.518 & 0.288 & 0.327 & 0.552 & 0.396 & 0.447 & 0.433 & 0.449 & 0.562 & 0.392 \\
\hline MRI & 0.147 & 0.192 & 0.062 & 0.225 & 0.350 & 1 & 0.256 & 0.461 & 0.398 & 0.132 & 0.285 & 0.358 & 0.212 & 0.321 & 0.175 & 0.301 \\
\hline SPM & 0.429 & 0.340 & 0.211 & 0.544 & 0.518 & 0.256 & 1 & 0.262 & 0.292 & 0.379 & 0.286 & 0.328 & 0.331 & 0.425 & 0.360 & 0.462 \\
\hline SGE & 0.273 & 0.317 & 0.036 & 0.325 & 0.288 & 0.461 & 0.262 & 1 & 0.625 & 0.299 & 0.591 & 0.480 & 0.313 & 0.458 & 0.214 & 0.275 \\
\hline SOO & 0.308 & 0.372 & 0.078 & 0.259 & 0.327 & 0.398 & 0.292 & 0.625 & 1 & 0.243 & 0.493 & 0.261 & 0.237 & 0.371 & 0.138 & 0.225 \\
\hline GFS & 0.403 & 0.382 & 0.100 & 0.375 & 0.552 & 0.132 & 0.379 & 0.299 & 0.243 & 1 & 0.453 & 0.354 & 0.268 & 0.399 & 0.523 & 0.410 \\
\hline TRF & 0.345 & 0.302 & 0.006 & 0.344 & 0.396 & 0.285 & 0.286 & 0.591 & 0.493 & 0.453 & 1 & 0.413 & 0.417 & 0.447 & 0.350 & 0.447 \\
\hline ITE & 0.324 & 0.402 & 0.093 & 0.375 & 0.447 & 0.358 & 0.328 & 0.480 & 0.261 & 0.354 & 0.413 & 1 & 0.470 & 0.386 & 0.480 & 0.491 \\
\hline FSY & 0.186 & 0.347 & 0.046 & 0.382 & 0.433 & 0.212 & 0.331 & 0.313 & 0.237 & 0.268 & 0.417 & 0.470 & 1 & 0.485 & 0.552 & 0.466 \\
\hline HMN & 0.447 & 0.535 & 0.052 & 0.593 & 0.449 & 0.321 & 0.425 & 0.458 & 0.371 & 0.399 & 0.447 & 0.386 & 0.485 & 1 & 0.561 & 0.564 \\
\hline TTT & 0.334 & 0.459 & 0.031 & 0.453 & 0.562 & 0.175 & 0.360 & 0.214 & 0.138 & 0.523 & 0.350 & 0.480 & 0.552 & 0.561 & 1 & 0.490 \\
\hline HSE & 0.386 & 0.537 & 0.075 & 0.532 & 0.392 & 0.301 & 0.462 & 0.275 & 0.225 & 0.410 & 0.447 & 0.491 & 0.466 & 0.564 & 0.490 & 1 \\
\hline
\end{tabular}

\subsection{Regression Analysis}

Table 4. The Regression Analysis of Influence Factors of Cultural Industry Longsighted Investment Strategy

\begin{tabular}{|c|c|c|c|c|c|c|}
\hline & \multicolumn{3}{|c|}{ Model I } & \multicolumn{3}{|c|}{ Model II } \\
\hline & Coefficient & $\mathrm{t}$ & $\mathrm{p}$ & Coefficient & $\mathrm{t}$ & $\mathbf{p}$ \\
\hline EFA & $0.978 * * *$ & 313.601 & 0 & $0.561 * * *$ & 13.531 & 0 \\
\hline DFA & $0.004 *$ & 1.704 & 0.093 & $0.225 * * *$ & 6.286 & 0 \\
\hline MCM & $0.016 * * *$ & 4.196 & 0 & $0.148 * * *$ & 2.971 & 0.003 \\
\hline PCM & $0.028 * * *$ & 7.498 & 0 & $0.205 * * *$ & 4.115 & 0 \\
\hline MIV & $0.026 * * *$ & 8.998 & 0 & $0.07 *$ & 1.81 & 0.071 \\
\hline SPM & $0.008 * *$ & 2.492 & 0.013 & $0.204 * * *$ & 5.078 & 0 \\
\hline SGE & $0.021 * * *$ & 5.436 & 0 & $0.033^{*}$ & 1.65 & 0.076 \\
\hline $\mathrm{SOO}$ & $0.025 * * *$ & 7.006 & 0 & $0.018 *$ & 1.691 & 0.096 \\
\hline HMN & $0.008 * *$ & 2.116 & 0.035 & $0.143 * * *$ & 2.683 & 0.008 \\
\hline TTT & $0.007 * *$ & 2.004 & 0.046 & $0.006 * *$ & 2.116 & 0.038 \\
\hline HSE & $0.028 * *$ & 7.788 & 0 & $0.081 *$ & 1.691 & 0.091 \\
\hline GFS & $0.001 * *$ & 2.085 & 0.032 & $0.007 *$ & 1.735 & 0.093 \\
\hline TRF & $0.005^{*}$ & 1.831 & 0.059 & $0.124 * *$ & 2.22 & 0.027 \\
\hline ITE & $0.005^{*}$ & 1.708 & 0.068 & $0.158 * * *$ & 2.572 & 0.01 \\
\hline FSY & $0.034 * * *$ & 8 & 0 & $0.331 * * *$ & 5.906 & 0 \\
\hline $\mathrm{C}$ & 0.932 & 38.374 & 0 & 0.837 & 9.152 & 0 \\
\hline Ajusted $R^{2}$ & \multicolumn{3}{|c|}{0.997} & \multicolumn{3}{|c|}{0.835} \\
\hline DW. & \multicolumn{3}{|c|}{2.079} & \multicolumn{3}{|c|}{2.052} \\
\hline $\mathrm{F}$ & \multicolumn{3}{|c|}{755.322} & \multicolumn{3}{|c|}{236.745} \\
\hline $\mathrm{P}$ & \multicolumn{3}{|c|}{0} & \multicolumn{3}{|c|}{0} \\
\hline
\end{tabular}

Note: (1)The explained variable in Model 1 is IVM; the explained variable in Model 2 is LTR; (2)

$*, * *$ and $* * *$ indicates significant at $10 \%, 5 \%$ and $1 \%$ respectively. 
From Model I in Table 4, we can see the regression coefficient between equity financing ability (EFA) and investment value maximization (IVM) is 0.978 , the two factors are significantly positively correlated at $1 \%$ level; the regression coefficient between debt financing ability (DFA) and investment value maximization (IVM) is 0.004 , the two factors are significantly positively correlated at $10 \%$ level; From Model II in figure 6, we can see the regression coefficient between equity financing ability (EFA) and long term investment resource (LTR) is 0,561 , the two factors are significantly positively correlated at $1 \%$ level; the regression coefficient between debt financing ability (DFA) and long term investment resource (LTR) is 0,225, the two factors are significantly positively correlated at $1 \%$ level; That is companies are more inclined to longsighted investment strategy when the external financing capacity is strong, Hypothesis 1 is further approved.

From Model I in Table 4, we can see the regression coefficient between external corporate governance factors manager competition market(MCM) and investment value maximization (IVM) is 0.016 , the two factors are significantly positively correlated at $1 \%$ level; the regression coefficient between product competition market (PCM) and investment value maximization (IVM) is 0.028 ,the two factors are significantly positively correlated at $1 \%$ level; the regression coefficient between internal corporate governance factors manager incentives(MIV) and investment value maximization (IVM) is 0.026 , the two factors are significantly positively correlated at $1 \%$ level; the regression coefficient between supervision mechanism(SPM) and investment value maximization (IVM) is 0.008 ,the two factors are significantly positively correlated at $5 \%$ level; From Model II in Table 4, we can see the regression coefficient between external corporate governance factors manager competition market(MCM) and long term investment resource (LTR) is 0.148 , the two factors are significantly positively correlated at $1 \%$ level; the regression coefficient between product competition market (PCM) and long term investment resource (LTR) is 0.205 , the two factors are significantly positively correlated at $1 \%$ level; the regression coefficient between internal corporate governance factors manager incentives(MIV) and long term investment resource (LTR) is 0.07 , the two factors are significantly positively correlated at $10 \%$ level; the regression coefficient between supervision mechanism(SPM) and long term investment resource (LTR) is 0.204 , the two factors are significantly positively correlated at $1 \%$ level. That is companies are more inclined to longsighted investment strategy when the corporate governance mechanism is more perfect, Hypothesis 2 is further approved.

From Model I in Table 4, we can see the regression coefficient between separation of government and enterprise (SGE) and investment value maximization (IVM) is 0,021 , the two factors are significantly positively correlated at $1 \%$ level; the regression coefficient between Separation of ownership and control (SOO) and investment value maximization (IVM) is 0,025 , the two factors are significantly positively correlated at $1 \%$ level; From Model II in Table 4, we can see the regression coefficient between separation of government and enterprise (SGE) and long term investment resource (LTR) is 0,033, the two factors are significantly positively correlated at $10 \%$ level; the regression coefficient between separation of ownership and control (SOO) and long term investment resource (LTR) is 0,018 , the two factors are significantly positively correlated at $10 \%$ level; That is companies are more inclined to longsighted investment strategy when the institution and system is better, Hypothesis 3 is further approved.

From Model I in Table 4, we can see the regression coefficient between humanity environment (HMN) and investment value maximization (IVM) is 0,008 , the two factors are significantly positively correlated at 5\% level; the regression coefficient between talent treatment (TTT) and investment value maximization (IVM) is 0.007, the two factors are significantly positively correlated at 5\% level; the regression coefficient between human settlement environment (HSE) and investment value maximization (IVM) 
is 0.028 , the two factors are significantly positively correlated at $5 \%$ level; From Model II in Table 4, we can see the regression coefficient between humanity environment (HMN) and long term investment resource (LTR) is 0.143, the two factors are significantly positively correlated at $1 \%$ level; the regression coefficient between talent treatment (TTT) and long term investment resource (LTR) is 0.006 , the two factors are significantly positively correlated at $5 \%$ level; the regression coefficient between human settlement environment (HSE) and long term investment resource (LTR) is 0.081 , the two factors are significantly positively correlated at $10 \%$ level. That is when the Talents environment is better, the company strategic investment can get needed talents more easily, and companies are more inclined to longsighted investment strategy ,Hypothesis 4 is further approved.

From Model I in Table 4, we can see the regression coefficient between government funds support (GFS) and investment value maximization (IVM) is 0,001 , the two factors are significantly positively correlated at $5 \%$ level; the regression coefficient between tax preference (TRF) and investment value maximization (IVM) is 0.005 , the two factors are significantly positively correlated at $10 \%$ level; From Model II in Table 4, we can see the regression coefficient between government funds support (GFS) and long term investment resource (LTR) is 0.007 , the two factors are significantly positively correlated at $10 \%$ level; the regression coefficient between tax preference (TRF) and long term investment resource (LTR) is 0.124 , the two factors are significantly positively correlated at $5 \%$ level. That is favorable policy is beneficial to promote cultural enterprise to implement longsighted investment strategy.

From Model I in Table 4, we can see the regression coefficient between integrity environment (ITE) and investment value maximization (IVM) is 0,005 , the two factors are significantly positively correlated at $10 \%$ level; the regression coefficient between financing system (FSY) and investment value maximization (IVM) is 0.034 , the two factors are significantly positively correlated at $1 \%$ level; From Model II in Table 4, we can see the regression coefficient between integrity environment (ITE) and long term investment resource (LTR) is 0.158 , the two factors are significantly positively correlated at $1 \%$ level; the regression coefficient between financing system (FSY) and long term investment resource (LTR) is 0.331 , the two factors are significantly positively correlated at $1 \%$ level. That is favorable financing ecological environment factors is beneficial to promote cultural enterprise to implement long-sight investment strategy.

\section{Conclusions and Recommendations}

From the above study, we find that the cultural industry companies are more inclined to longsighted investment strategy when they have large external financing capacity, a more perfect governance mechanism, sound systems and good talents environment. Thus, it is necessary to upgrade external financing capacity, perfect governance mechanism, and optimizing systems and talents environment in order to improve competitiveness of Chinese cultural industry and realize a transformation of investment strategy from shortsighted to longsighted. 


\subsection{Innovating Management Systems to Speed up Cultural Industry Market}

The Chinese cultural industry is originated from public cultural undertakings. A thorough cultural change is needed from "undertakings" to "industry" and "enterprise" for sound cultural industry systems. The market investment and financing subjects should be shaped based on market oriented and market economic development requirements, so that they can bear the risks in cultural market investment and financing, and become the main bodies of market operation by their own decision, development and self-control. By this way, the governmental departments will withdraw from a principal status gradually as a cultural financing subject, and the market can play a basic role in allocation of cultural resources and elements. In view of current leading role of state-owned cultural enterprise in Chinese cultural industry development, all companies based on sate-owned capital may establish the corporate governance structure in terms of stockholding systems to ensure their steady operation and long-term development in fierce market competition.

\subsection{Perfecting Corporate Governance Mechanism to Provide Motive Force for Development of Cultural Industry Financing}

The first thing is to perfect external governance mechanism, establish manager market and apply market competition mechanism; select corporate executives by market competition and weaken government-delegating system; break government monopoly to state-owned cultural products, and place cultural products in market for competition, and provide external motivation for cultural industry financing. The second thing is to improve internal management mechanism, break the equalitarianism of state-owned cultural enterprises, and give the share incentive to senior executives in cultural enterprises; crack the managers' and the owners' agency problems in investment and financing to realize their same objectives.

\subsection{Developing Multi-Financing Modes to Provide Fund Guarantees for Development of Cultural Industries}

The failure of external financing capacity is an important factor confining development of Chinese cultural industry. Therefore, establish multi-level capital credit market (loans in intellectual property and earnings mortgages particularly) by making full use of domestic and foreign financial markets (stock and bond markets particularly), and build a diversified, multilevel and multi-channel cultural industry financing system by cultural investment funds and venture investment; promote the full cooperation of cultural and financial industries, encourage all kinds of financial institutes to innovate financial products, improve the financial services for cultural industries, and guide social capital into cultural industries.

\subsection{Optimizing Talents Environment and Providing Intellectual Support to Cultural Industries}

Talents are the bottleneck to confine strategic investment to Chinese cultural industries. In order to optimize talents environment and provide intellectual support to cultural industries, the followings should be done: first, give full scope to the talents; second, bring in needed personnel, renew ideas in their introduction and carry out the policy of "flexible flow" of talents for win-win; third, train personnel, and establish the mechanisms of training, selection, introduction and incentives for cultural talents; create a good entrepreneurial environment, and gather a lot of high-quality energetic professional cultural personnel, creative talents and talented managers, so as to provide potent intelligent guarantee for the longsighted investment strategy of cultural enterprises. 


\section{Acknowledgments}

Supported by the Henan Province Project of Key Research Institute of Humanities and Social Sciences at Universities, Collaborative Innovation Center for Aviation Economy Development of Henan Province, National Social Science Fund of China (No. 13BGL051 and No. 14BGL037), Collaborative Innovation Center for Aviation Economy Development of Henan Province and Zhengzhou Soft Science Research Project (20141056).

\section{References}

[1] L. A. Jeng and P. C. Wells, "The Determinants of Venture Capital Funding: Evidence across Countries, Journal of Corporate finance, vol. 6, (2000), pp. 241-289.

[2] A. J. Scott, "Cultural-products Industries and Urban Economic Development: Prospects for Growth and Market Contestation in Global Context. Urban Affairs Review, vol. 39, no. 4, (2004), pp. 461-490.

[3] Y. DAI, "Effects of Financing Factors of Cultural Industry on Investment Behavior of Chinese cultural industry listed company", The Theory and Practice of Finance and Economics, vol. 03, (2015), pp. 55-59.

[4] F. Modigliani and M. H. Miller, "The Cost of Capital, Corporation Finance and the Theory of Investment", The American Review, vol. 48, no. 3, (1958), pp. 261-297.

[5] S. C. Myers and N. S. Majluf, "Corporate Finance and Investment Decisions When Firms Have Information that Investors do not have", Journal of Financial Economics, vol. 13, no. 2, (1984), pp. 187-221.

[6] S. Cleary, "The Relationship between Firm Investment and Financial Status", The Journal of Finance, vol. 54, no. 4, (1999), pp. 673-692.

[7] X. H. Le, "Research on the Relationship between Influential Factors and Investment Performance in Cultural Industry", vol. 5, (2011), pp. 11-16.

[8] C. Camarero, M. J. Garrido and E. Vicente, "How Cultural organization's Size and Funding Influence Innovation and Performance: the Case of Museums", Journal of Cultural Economics, vol. 35, (2011), pp. 247-266.

[9] H. YUAN and Z. R. WU, "An Empirical Analysis on Calculation and Influencing Factors of Provincial Cultural Industry Efficiency in China”, Soft Science, vol. 3, (2012), pp. 72-77.

[10] Q. H. LU, "Investment and Financing in Industrial Development of Cultural Resources", Journal of Shanxi Finance and Economics University, vol. 5, (2005), pp. 68-73.

[11] M. Keane, "Creative Industries in China: Four Perspectives on Social Transformation", International Journal of Cultural Policy, vol. 15, no. 4, (2009), pp. 431-434.

\section{Author}

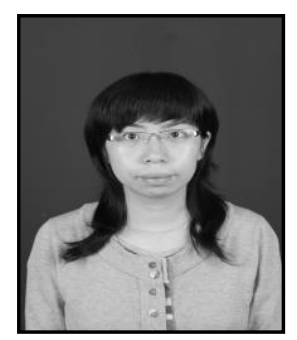

Zhang Guiling, was born in 1983, Henan China. CIMA Advanced Diploma in Management Accounting. She received the Master degree of management in Nankai University in 2006. Now she is a lecture in Zhengzhou Institute of Aeronautical Industry Management. Her current research interests include $R \& D$ investment and investment efficiency. 